\title{
POLA PRINSIP KEMITRAAN DALAM PENGEMBANGAN PARIWISATA DI KABUPATEN PURBALINGGA PROVINSI JAWA TENGAH
}

\author{
Dahyar Daraba ${ }^{1}$ Sari Indah Murwani ${ }^{2}$, Frans Dione ${ }^{3}$, Rudi Salam ${ }^{3}$ \\ Institut Pemerintahan Dalam Negeri (IPDN) Jatinangor, Indonesia ${ }^{1,2,3}$ \\ Unversitas Negeri Makassar ${ }^{4}$ \\ Email: dahyardaraba@ipdn.ac.id ${ }^{1}$, dahyardaraba@ipdn.ac.id ${ }^{2}$, fransdione@ipdn.ac.id ${ }^{3}$, \\ rudisalam@unm.ac.id ${ }^{4}$
}

\begin{abstract}
In the development of tourism in the region requires planning, strategy and innovation where managers and governments must seriously develop their regional tourism sector to improve the regional economy and society is descriptive qualitative with an inductive approach. Sources of data obtained from primary and secondary data. Data collection is done by observation, interviews, and documentation. Data analysis techniques through data reduction, data presentation, and drawing conclusions. The results showed that the partnership pattern in the development of tourism in Purbalingga District had gone quite well but not yet at maximum. This is stated by fulfilling the 3 principles of partnership namely mutual respect, respect and trust. To realize partnerships in tourism it is necessary to agree on the perception of partnerships between the private sector, the government and the community.
\end{abstract}

Keywords: Partnership Pattern, Tourism, Regional Tourism

\begin{abstract}
ABSTRAK
Abstrak: Dalam pengembangan pariwisata di kawasan ini membutuhkan perencanaan, strategi dan inovasi dimana manajer dan pemerintah harus secara serius mengembangkan sektor pariwisata regional mereka untuk meningkatkan ekonomi regional dan masyarakat bersifat deskriptif kualitatif dengan pendekatan induktif. Sumber data diperoleh dari data primer dan sekunder. Pengumpulan data dilakukan dengan observasi, wawancara, dan dokumentasi. Teknik analisis data melalui reduksi data, penyajian data, dan penarikan kesimpulan. Hasil penelitian menunjukkan bahwa pola kemitraan dalam pengembangan pariwisata di Kabupaten Purbalingga sudah berjalan cukup baik tetapi belum maksimal. Ini dinyatakan dengan memenuhi 3 prinsip kemitraan yaitu saling menghormati, menghormati dan kepercayaan. Untuk mewujudkan kemitraan dalam pariwisata, perlu disepakati persepsi tentang kemitraan antara sektor swasta, pemerintah, dan masyarakat.
\end{abstract}

Kata kunci: Pola Kemitraan, Pariwisata, Pariwisata Daerah 


\section{PENDAHULUAN}

Pariwisata merupakan salah satu urusan pilihan dalam penyelenggaraannya dibagi antara pemerintahan pusat maupun daerah (Deng, Hu, \& Ma, 2019; Park, Lee, Yoo, \& Nam, 2016; Pike \& Ives, 2018; Situmorang, Trilaksono, \& Japutra, 2019). Pemerintah daerah melaksanakan urusan pilihan yaitu pariwisata berdasarkan potensi, proyeksi penyerapan tenaga kerja, dan pemanfaatan lahan. Di era globalisasi saat ini pariwisata merupakan penyumbang terbesar pendapatan negara (Andrades \& Dimanche, 2017; Chookaew, Chanin, Charatarawat, Sriprasert, \& Nimpaya, 2015; Jafari \& Scott, 2014; Jonsa \& Salwan, 2018; Kapera, 2018).

Indonesia adalah negara yang kaya raya, selain sumber daya alam melimpah juga adat istiadat budaya bahasa agama yang beraneka ragam. Disetiap daerah memiliki ciri khas kebudayaan serta flora fauna dan kekayaan alam yang menjadi potensi pariwisata daerah. Hakikat pariwisata Indonesia bertumpu pada keunikan dan kekhasan budaya alam serta hubungan antar manusia (Li, Xu, Tang, Wang, \& Li, 2018; Richards, 2018; Said, Salam, Akib, \& Baharuddin, 2017; Said, Wahidiyat, Andayani, Harifuddin, \& Salam, 2017). Pariwisata juga didukung dengan dikeluarkannya Undang-Undang Nomor 10 Tahun 2009 tentang Kepariwisataan. Dalam Pasal 29 disebutkan bahwa wewenang pemerintah daerah yaitu membangun, mengkoordinasi dan menyelenggarakan kepariwisataan provinsi. Hasil penelitian mengenai potensi pariwisata daerah dilihat dari berbagai aspek budaya, agama dan kekayaan alam seperti: Harnida \& Tahir,2012; Pudianti, 2012; Susilo \& Soeroso, 2014.

Kabupaten Purbalingga adalah sebuah Kabupaten di Provinsi Jawa Tengah yang memiliki keunggulan dan keunikan di bidang industri dan pariwisata. Pada tahun 2016 tercatat ada 1,58 juta wisatawan datang ke Purbalingga. Jumlah tersebut menjadikan Purbalingga menempati posisi ke 4 jumlah wisatawan terbanyak di Jawa tengah. Tiap- tiap kecamatan di Kabupaten Purbalingga memiliki karakteristik objek dan daya tarik yang sangat kompetitif sebagia produk wisata yang harus dikelola secara optimal. Objek dan daya tarik wisata yang dapat dinikmati seperti wisata alam, wisata buatan, wisata edukasi dan wisata sejarah. Dengan visi purbalingga "Purbalingga yang mandiri dan berdaya saing menuju masyarakat sejahtera yang berakhlak mulia".

Berdasarkan misi ke 5 Kabupaten Purbalingga tersebut, maka dapat disimpulkan bahwa Kabupaten Purbalingga memiliki fokus mempercepat pertumbuhan dan pemerataan ekonomi rakyat dengan berorientasi pada kemitraan. Dalam Rencana Pembanguanan Jangka Menengah (RPJMD) yang mengacu pada RPJP menyatakan bahwa sektor pariwisata saat ini sangat penting dalam pengembangan perekonomian daerah. Sektor pariwisata tumbuh dari upaya memanfaatkan potensi alam maupun dengan membuat objek wisata buatan yang memiliki kekhasan dan keunggulan. Usaha pengembangan kepariwisataan juga didukung dengan Peraturan Daerah Kabupaten Purbalingga No 11 Tahun 2015 tentang Rencana Induk Pembangunan Kepariwisataan Tahun 2015-2025. Kinerja urusan pariwisata dapat dilihat dari beberapa indikator diantaranya yaitu program pengembangan destinasi pariwisata ada 4 indikator jumlah objek wisata, jumlah wahana baru pada objek wisata, jumlah kelompok sadar wisata/ pemandu wisata, jumlah penyerapan tenaga kerja di sektor pariwisata. Dan pada program pengembangan promosi pariwisata terdapat indikator yaitu nilai tambah sektor- sektor pendukung pariwisata, Product Domestic Regional Bruto (PDRB) sektor hotel dan restoran, Produk Domestic Regional (PDR) sektor transportasi, jumlah kunjungan wisatawan, rata-rata tingkat hunian hotel, ratarata lama tinggal wisatawan, jumlah Pendapatan Asli Daerah (PAD) tingkat pariwisata.

Pengembangan pariwisata Kabupaten Purbalingga kurang bekerjasama antara pemerintah, swasta dan masyarakat. Kecamatan Karangreja yang merupakan kawasan pariwisata kurang menjalin kerjasama dengan pihak swasta dan investor sehingga kurang maksimal dalam pengembangannya. Kerjasama dengan swasta baru akan dilakukan dengan investor asal Korea Selatan tahun 2017 ini. Rencananya akan di bangun resort yang dilengkapi dengan taman bunga smile flower, cottage, kereta listrik, camping site, horse riding square, dan restoran. Dengan pembangunan resort diharapkan akan menambah daya tarik wisatawan untuk berkunjung ke Purbalingga, membuka lapangan pekerjaan bagi masyarakat sekitar dan meningkatkan pendapatan Kabupaten 
Purbalingga. Kerjasama pengembangan pariwisata yang dilakukan dengan pihak swasta juga harusnya berkaitan dengan hotel, yang memberikan fasilitas penginapan bagi wisatawan baik wisatawan nusantara maupun wisatawan mancanegara.

Banyak objek wisata di Purbalingga berbanding terbalik dengan ketersediaan hotel, penginapan, cottage, home stay ataupun yang sejenisnya. Tercatat bahwa selama tahun 2015 hanya ada satu penambahan penginapan/ hotel dari 12 menjadi 13 hotel, sedangkan jumlah kamar dan tempat tidurnya malah mengalami penurunan. Bagi para wisatawan luar kabupaten yang membutuhkan penginapan/ hotel sepeti ada sebuah stigma tak tertulis "biar rekreasinya di Purbalingga tapi nginapnya tetap di Banyumas". Ini merupakan sebuah PR bagi pemerintah Kabupaten Purbalingga untuk bisa menarik para wisatawan yang berwisata di Purbalingga tetap menginap di Purbalingga Kondisi tersebut menunjukan bahwa pemerintah daerah belum memiliki komitmen dalam menjalin kerjasama yang konsisten antara pemerintah daerah, pihak swasta dan masyarakat karena untuk mengembangkan pariwisata di daerah, diperlukan kerjasama, koordinaasi dan sinergi yang kuat antara pemerintah daerah dan pihak swasta terutama dalam pembuatan kebijakan regulasi, program, dan implementasi.

Permasalahan-permasalahan dibidang pariwisata ini tentunya menjadi pemicu bagi Pemerintah daerah khususnya Dinas Pemuda Olahraga dan Pariwisata Kabupaten Purbalingga kedepan dalam upaya pengembangan pariwisata yang mampu meningkatkan pendapatan objek wisata dan jumlah kunjungan wisatawan ke Kabupaten Purbalingga agar mengalahkan 3 peringkat teratas di Jawa Tengah. Sehingga perlu dilakukan pengkajian lebih dalam hubungan kesinergian dan kemitraan antar pemerintah daerah, swasta dan masyarakat.

\section{KAJIAN PUSTAKA}

Kemitraan dan model pemberdayaan dilihat dari kata partnership, dan berasal dari akar kata partner. Partner dapat diterjemahkan "pasangan, jodoh, sekutu atau kompanyon". Sedangkan partnership diterjemahkan menjadi persekutuan atau perkongsian. Bertolak dari sini maka kemitraan dapat dimaknai sebagai suatu bentuk persekutuan antara dua pihak atau lebih yang membentuk suatu ikatan kerjasama atas dasar kesepakan dan rasa saling membutuhkan dalam rangka meningkatkan kapasitas dan kapabilitas disuatu bidang usaha tertentu, atau tujuan tertentu, sehingga dapat memperoleh hasil yang lebih baik.

Kemitraan (partnership) antara pemerintah daerah, swasta dan masyarakat dalam berbagai kegiatan pembangunan di daerah memberikan manfaat dan dampak positif yang sangat besar. Manfaat positif bagi pihakpihak yang bermitra, terutama pihak swasta dan masyarakat adalah memperluas lapangan kerja dan meningkatkan pendapatan, yang selanjutnya diharapkan akan meningkatkan kesejahteraan masyarakat. Kemitraan pembangunan akan menimbulkan dampak positif, yaitu menumbuhkembangkan peningkatan produksi dan produktivitas, peningkatan aliran investasi, kelancaran distribusi dan pemasaran, aksesibilitas dan mobilitas penduduk, peningkatan keterkaitan pembangunan ekonomi dan interaksi sosial antara daerah atau wilayah. Keberhasilan kemitraan pembangunan berarti pula akan meringankan beban keuangan bagi pemerintah daerah.

Goles dan Alexandrova mengenai faktor yang mempengaruhi keberhasilan kemitraan terlihat bahwa para ahli terebut menentukan dari beberap perspektif yaitu dari sudut pandang obyek dan subyek hingga evaluasi dari kemitraan itu. Dalam mengembangkan pariwisata peran kemitraan sangat dibutuhkan. Pariwisata hendaknya tersedianya atraksi wisata sebagai daya tarik bagi wisatawan untuk mengunjungi daerah tujuan wisata, memiliki fasilitas yang mendukung pengembangan pariwisata yang menarik. Penyediaan sarana dan prasana dapat dilakukan oleh pemerintah daerah, masyarakat sekitar dan swasta. Maka dengan terlengkapinya fasilitas tersebut pengunjung akan merasakan kenyamanan dan tertarik untuk datang ke suatu objek wisata. Selain penyediaan fasilitas yang lengkap juga harus didukung dengan kelestarian alam, budaya, dan lingkungan sekitar. Pengembangan pariwisata dikatakan berhasil apabila hal tersebut terpenuhi.

Supaya diperoleh hasil yang optimal
maka pengembangannya memerlukan
perencanaan yang matang dan cermat serta
pemikiran yang luas mencakup unsur-unsur
yang berbentuk fisik dan institusional. Ada
beberapa komponen dasar yang harus


dipertimbangkan dalam penyusunan rencana pariwisata supaya dihasilkan rumusan rencana pariwisata yang komprehensif, sesuai dengan kondisi lingkungan setempat dan sesuai dengan sasaran yang akan dituju, sehingga dapat direalisasikan pembangunan pariwisata yang berkelanjutan dan bermanfaat secara optimal. George McIntyre (1993) dalam Wardiyanto (2011) menyatakan bahwa komponen dasar pariwisata terdiri dari: 1) Atraksi wisata dan Kegiatan Wisata yang menjadi objek/ daya tarik wisata, 2) Fasilitas Akomodasi beserta pelayanannya, 3) Fasilitas transportasi dan pelayanan lainnya, 4) Sumberdaya manusia, 5) Fasilitas pelayanan lainnya dan 6) Unsur-unsur institusional. Sedangkan menurut Sedarmayanti (2014:28) komponen-komponen pariwisata meliputi: 1) Objek dan daya tarik wisata, 2) Akomodasi, 3) Angkutan wisata, 4) Saranan dan fasilitas wisata, dan 5) Prasarana wisata.

Berdasarkan pendapat ahli tersebut dapat disimpulkan bahwa komponen dasar yang harus dipertimbangkan untuk memperoleh hasil yang optimal dalam pengembangan pariwisata yaitu meliputi daya tarik /atraksi wisata yang dapat membuat wisatawan terkesan dapat berupa objek maupun kegiatan yang ditunjukan secara khusus, akomodasi seperti hotel, penginapan, losmen dll, transportasi berupa infrastruktur jalan yang dilalui wisatawan dan alat/sarana transportasi berupa terminal, mobil, bandara, area parkir, dan sumberdaya manusia yang berperan sebagai pelaku wisata maupun pengelola usaha wisata. Komponen dasar tersebut harus dijadikan pertimbangan dalam membuat kerangka pengembangan dan pemasaran pariwisata serta dijadikan bahan kajian supaya diperoleh kajian pariwisata yang komprehensif.

$$
\text { Komponen dasar dalam }
$$
pengembangan pariwisata tentunya, tidak akan terwujud tanpa adanya berbagai kemitraan yang mengawal setiap kegiatan yang dilaksanakan oleh pengembangan pariwisata. Tentunya membutuhkan masyarakat setempat, stakeholders, pemerintah daerah, pihak swasta dan pihak lainnya yang berkepentingan dan mewujudkan pariwisata yang tertata yang mampu memberikan value cration.

\section{METODE PENELITIAN}

Peneliti menggunakan desain penelitian kualitatif yakni sebuah penelitian yang mendeskripsikan kejadian berupa data yang sebenarnya terjadi dilingkungan dengan cara mengembangkan berbagi teori, mengumpulkan data lalu menafsirkannya kedalam suatu analisis berdasarkan kajian teori yang sebelumnya sudah ditelaah (Creswell \& Creswell, 2018). Informan yang menjadi sumber data dalam penelitian seperti: a) Kepala Dinas Pemuda Olahraga dan Pariwisata, b) Sekertaris Dinas Pemuda dan Olahraga dan Pariwisata, c) Kepala Bidang Pariwisata Dinas Pemuda Olahraga dan Pariwisata, d) Kepala Seksi Promosi dan Pemasaran Pariwisata, e) Kepala Seksi Pengembangan Destinasi Dan SDM Pariwisata, f) Kepala Seksi Industri dan Usaha Pariwisata, g) Tokoh Masyarakat/ masyarakat sekitar kawasan objek wisata, h) Pelaku usaha wisata/ pengelola objek wisata, i) Pemandu Wisata/ Petugas wisata, j) Kelompok Sadar Wisata, k) Wisatawan, 1) Pemilik restoran, m) Pemilik hotel. Peneliti memilih informan tersebut karena dianggap mampu memberikan informasi akurat mengenai situasi dan kondisi berdasarkan latar belakang penelitian dan merupakan keterwakilan dari masing-masing stakeholder yaitu pemerintah diwakilkan oleh Dinas Pemuda Olahraga dan Pariwisata, swasta, dan masyarakat. lokasi penelitian yang dipilih oleh penulis bertempat di Kabupaten Purbalingga Provinsi Jawa Tengah. Peneliti menggunakan beberapa cara pengumpulan data seperti: a) observasi, b), wawancara, dan c) dokumentasi. Teknik analis data kualitatif menggunakan analisis interatif yaitu: a) Pengumpulan data, b) Penyajian data, c) Kondensasi data, d) Kesimpulan-kesimpulan (penarikan/verifikasi) (Miles, Huberman, \& Saldana, 2014).

\section{HASIL PENELITIAN DAN PEMBAHASAN Hasil Penelitian}

Destinasi wisata di Kabupaten Purbalingga memberikan kesempatan kepada para usahawan untuk berkonstribusi dalam mendukung aktivitas usaha parwisata. Usaha pariwisata yang diterbitkan tanda daftar usaha pariwisata (TDUP) Dinas Pemuda Olahraga dan Pariwisata Kabupaten Purbalingga terdapat 51 usaha pariwisata yang sudah memiliki tanda daftar usaha pariwisata (TDUP) antara lain usaha penyelenggaraan kegiatan hiburan dan rekresi, usaha pelayanan akomodasi, usaha jasa makanan dan minuman, usaha jasa perjalanan wisata, usaha jasa informasi pariwisata, usaha jasa penyelenggaraan pertemuan, perjalanan insentif, koferensi dan pameran, usaha daya 
tarik pariwisata, usaha wisata tirta, dan usaha jasa transportasi wisata. Selain itu, bekerjasama dengan badan usaha milik desa (Bumdes) setempat. Walaupun pada kenyataannya masih terdapat beberapa usaha pariwisata yang belum memiliki tanda daftar usaha pariwisata sehingga dari pihak pemerintah mendatangi usaha tersebut untuk mensosialisasi dan memberi informasi agar segera memiliki tanda daftar usaha pariwisata.

Salah satu indikator untuk menciptakan suatu kesetaraan atau keseimbangan didalam melakukan suatu kemitraan adalah harus saling menghormati, menghargai dan percaya sehingga dalam pola kemitraan dalam pengembangan pariwisata di Kabupaten Purbalingga antara pemerintah daerah, swasta dan masyarakat harus saling menghormati, menghargai dan percaya.

Saling menghormati, menghargai dan percaya setiap orang merupakan hal yang sangat terpuji dan mampu mewujudkan keterikatan batin antara satu dengan lainnya. Sebagai wujud dari penghormatan tentunya dapat dilihat dari komunikasi yang disampaikan oleh seseorang baik secara lisan maupun dengan pembuktian atau memberikan hal yang sangat berharga. Sebagai elemen masyarakat baik pengunjung dan masyarakat ditempat destinasi wisata tentunya secara tidak langsung dalam pemberian penghormatan. Sebagai bentuk penghormati yang diberikan oleh pengelola destinasi wisata saling menghargai dalam melakukan silaturahmi, komunikasi dan koordinasi dengan mereka. Selain itu, memberikan hak-hak sebagai pengunjung maupun masyarakat sekitar seperti: pemberian tarif parkir kami samakan dengan yang berada diluar destinasi wisata sehingga pengunjung tidak merasa dirugikan. Pedagang yang merupakan warga sekitar tidak kami tarik retribusi dan bagi masyarakat setempat diperbolehkan masuk di tempat destinasi wisata secara gratis.

Sebagai wujud penghargaan juga melibatkan masyarakat sebagai pengelola, pengurus/ karyawan dan pedagang didalam destinasi wisata, dan terlibat dalam kegiatan sosial masyarakat sehingga dampak adanya destinasi wisata juga dirasakan masyarakat baik yang terlibat maupun yang tidak terlibat. Agar kekerabatan antara satu sama lain terwujud, maka pemerintah melakukan pembinaan misal dalam hal pengawasan. Pada obyek usaha pariwisata kita datangi dan kita tanya untuk mendekatkan pemerintah dengan usaha pariwisata tersebut kemudian pemerintah melakukan sosialisasi untuk berTDUP (tanda daftar usaha pariwisata).

Saling menghormati, menghargai dan percaya yang nantinya akan mencitakan kesetaraan atau keseimbangan dalam kemitraan antara pemerintah daerah, swasta dan masyarakat di lakukan dengan cara dan teknik masing-masing pihak. Pihak swasta yang dalam pengelolaannya dilakukan sendiri tanpa ikut campur pemerintah tetap menghormati dan menghargai pemerintah dengan menaati segala peraturan yang ditetapkan pemerintah seperti halnya mendaftarkan usaha pariwisatanya kepada pemerintah untuk memilliki tanda daftar usaha pariwisata (TDUB) walaupun belum semua melakukan hal tersebut dimana pemerintah sangat perhatian dengan mendatangi tempat usaha pariwisata tersebut sekaligus sebagai pengawasan sedangkan kepada masyarakat dengan cara melibatkan masyarakat didalam usaha pariwisata dan ikut kerlibat didalam kegiatan sosial masyarakat. Cara yang dilakukan Desa wisata yaitu melibatkan masyarakat baik untuk berinvestasi maupun sebagai pengurus, melakukan evaluasi dan pertemuan musyawarah kepada masyarakat sehingga masyarakat percaya, didukung juga dengan adanya badan pengawas di dalam BUMDes.

\section{Pembahasan}

Saling menghargai, Penghargaan dan percaya yang diberikan oleh pemerintah selain sebagai bentuk apresiasi juga sebagai bentuk menciptakan kesetaraan atau keseimbangan dalam bermitra. Sebagai acuan dalam melaksanakan kewajiban, hak dan penghargaan maka pemerintah daerah, swasta, dan masyarakat berpedoman dengan dalam (Undang-Undang Republik Indonesia, 2009 Nomor 10 tahun 2009) tentang kepariwisataan antara lain yang mengatur kewajiban dan hak pemerintah dan pemerintah daerah, kewajiban dan hak pengusaha pariwisata hak orang, hak prioritas orang didalam/ sekitar destinasi, penghargaan dan lain-lain.

Adanya penghargaan, kewajiban dan ikatan sehingga menciptakan suatu kesetaraan atau keseimbangan terhadap pelaksanaan kemitraan yang dijalin pemerintah daerah, swasta dan masyarakat dalam pengembangan pariwisata di Kabupaten Purbalingga adalah sudah cukup baik. Pemerintah daerah, swasta 
dan masyarakat sebagian besar sudah melaksanakan kewajibannya masing-masing walapun ada beberapa pihak yang belum melaksanakan kewajibannya secara maksimal. Penghargaan yang diberikan dari masingmasing pihak dilakukan agar menciptakan hubungan kerjasama yang sinergi sehingga pengembangan pariwisata akan terus mengalami kemajuan. Sama halnya dengan ikatan yang telah dituangkan dalam surat perjanjian menjadikan salah satu upaya agar lebih mengikat secara formal dan menciptakan kesetaraan atau keseimbangan antar pihak yang terkait. Ketentuan lebih lanjut mengenai penghargaan, kewajiban dan ikatan diatur dalam UU No 10 Tahun 2009 mengenai kepariwisataan. Pola kemitraan tentunya harus mengembangkan prinsip yang saling sinergi antara satu sama lain. Sehingga keakraban saling memiliki akan destinasi wisatawa yang ada, hal ini sesuai dengan berbagai penelitian yang diungkapkan oleh Graci, 2013; Hakim, Zaenuri, \& Fridayani, 2019; Mtapuri \& Giampiccoli, 2016; Saarinen, Rogerson, \& Manwa, 2013; Tomaselli, 2012; Zach \& Hill, 2017.

\section{KESIMPULAN DAN SARAN Kesimpulan}

Pola Prinsip kemitraan antara Pemerintah Daerah, swasta, dan masyarakat dalam pengembangan pariwisata di Kabupaten Purbalingga sudah berjalan msekipun belum terlaksana secara maksimal. Dalam konteks realitas dilapangan terdapat 3 prinsip kemitraan yaitu sikap saling menghormati, menghargai dan percaya antara pemerintah daerah, swasta dan masyarakat. Wujud dari prinsip kemitraan tersebut, tentunya akan terwujud pengembangan destinasi parwisata yang saling bersinergi antara satu sama lain. Sehingga kunjungan wisatawan bukan hanya dilihat dari jumlah kunjungan yang bertambah melainkan kenyamanan antara pengujung, stakeholder dan masyarakat setempat.

\section{Saran}

Disarankan bahwa pola kemitraan harus dilaksanakan sesuai dengan peraturan yang telah ditetapkan. Selain itu, apabila terdapat masalah dilapangan diharapkan mampu untuk mencarikan solusi yang terbaik. Sehingga tidak ada yang merasa dirugikan.

\section{DAFTAR PUSTAKA}

Andrades, L., \& Dimanche, F. (2017). Destination competitiveness and tourism development in Russia: Issues and challenges. Tourism Management, 62, 360-376.

https://doi.org/https://doi.org/10.1016/j.to urman.2017.05.008

Chookaew, S., Chanin, O., Charatarawat, J., Sriprasert, P., \& Nimpaya, S. (2015). Increasing halal tourism potential at Andaman Gulf in Thailand for Muslim country. Journal of Economics, Business and Management, 3(7), 739-741.

Creswell, J. W., \& Creswell, J. D. (2018). Research and Design Qualitative, Quantitative and Mixed Methods Approaches. In Thousand Oaks California.

Deng, T., Hu, Y., \& Ma, M. (2019). Regional policy and tourism: A quasi-natural experiment. Annals of Tourism Research, 74 $1-16$. https://doi.org/https://doi.org/10.1016/j.a nnals.2018.10.001

Graci, S. (2013). Collaboration and partnership development for sustainable tourism. Tourism Geographies, 15(1), 25-42.

Hakim, A. R., Zaenuri, M., \& Fridayani, H. D. (2019). Collaborative Governance In Managing Educative Tourism Of Jogja Exotarium In Sleman Regency 2019. Journal of Governance and Public Policy, 6(2), 195-215.

Harnida, H., \& Tahir, M. (2012). Peran Pemerintah Daerah Dalam Pengembangan Obyek Wisata Hutan Batu RammangRammang di Kabupaten Maros. Otoritas: Jurnal Ilmu Pemerintahan, 2(2).

Jafari, J., \& Scott, N. (2014). Muslim world and its tourisms. Annals of Tourism Research, 44 , $1-19$. https://doi.org/https://doi.org/10.1016/j.a nnals.2013.08.011

Jonsa, A., \& Salwan, Y. (2018). Kinerja Kantor Pelayanan Pajak Pratama (KPPP) Meulaboh dalam Meningkatkan Pelayanan Minat Wajib Pajak. Jurnal Public Policy, 3(2). 
Kapera, I. (2018). Sustainable tourism development efforts by local governments in Poland. Sustainable Cities and Society, 40, 581-588. https://doi.org/https://doi.org/10.1016/j.sc s.2018.05.001

Li, J., Xu, L., Tang, L., Wang, S., \& Li, L. (2018). Big data in tourism research: A literature review. Tourism Management, 68, 301-323. https://doi.org/https://doi.org/10.1016/j.to urman.2018.03.009

Miles, M. B., Huberman, A. M., \& Saldana, J. (2014). Qualitative Data Analysis: A Methods Sourcebook (3 ed.). United States of America: Sage Publications.

Mtapuri, O., \& Giampiccoli, A. (2016). Towards a comprehensive model of community-based tourism development. South African Geographical Journal, 98(1), 154-168.

Park, J. H., Lee, C., Yoo, C., \& Nam, Y. (2016). An analysis of the utilization of Facebook by local Korean governments for tourism development and the network of smart tourism ecosystem. International Journal of Information Management, 36(6, Part B), $1320-1327$. https://doi.org/https://doi.org/10.1016/j.iji nfomgt.2016.05.027

Pike, S., \& Ives, C. (2018). The restructuring of New Zealand's Regional Tourism Organisations. Journal of Destination Marketing \& Management, 9, 371-373. https://doi.org/https://doi.org/10.1016/j.jd mm.2017.11.005

Pudianti, A. (2012). Perpaduan Budaya Lokal dan Potensi Fisik sebagai Daya Tarik Wisata Pedesaan di Sleman, Daerah Istimewa Yogyakarta.

Republik Indonesia. Undang-Undang Republik Indonesia No. 10 Tahun 2009 Tentang Kepariwisataan.

Richards, G. (2018). Cultural tourism: A review of recent research and trends. Journal of Hospitality and Tourism Management, 36, 12-21.

https://doi.org/https://doi.org/10.1016/j.jh tm.2018.03.005

Saarinen, J., Rogerson, C. M., \& Manwa, H. (2013). Tourism and the millennium development goals: Tourism, local communities and development. Routledge.

Said, F., Salam, R., Akib, H., \& Baharuddin, A. (2017). An Analysis of Tourism Visit Trend. 149(Icest), 34-36.

Said, F., Wahidiyat, A., Andayani, D. D., Harifuddin, H., \& Salam, R. (2017). Development of Travel Attractions Through the Design of Google SketchUp Based Coastal Tourist Map (Pengembangan Daya Tarik Wisata Melalui Perancangan Peta Wisata Pantai Berbasis Google SketchUp). Pekommas, 2(2).

Situmorang, R., Trilaksono, T., \& Japutra, A. (2019). Friend or Foe? The complex relationship between indigenous people and policymakers regarding rural tourism in Indonesia. Journal of Hospitality and Tourism Management, 39, 20-29. https://doi.org/https://doi.org/10.1016/j.jh tm.2019.02.001

Susilo, Y. S., \& Soeroso, A. (2014). Strategi pelestarian kebudayaan lokal dalam menghadapi globalisasi pariwisata: Kasus Kota Yogyakarta. Jurnal Penelitian BAPPEDA Kota Yogyakarta, 4, 3-11.

Tomaselli, K. G. (2012). Cultural tourism and identity: Rethinking indigeneity. Martinus Nijhoff Publishers.

Zach, F. J., \& Hill, T. L. (2017). Network, knowledge and relationship impacts on innovation in tourism destinations. Tourism Management, 62, 196-207. 